\title{
Effect of carbendazim-8-oxyquinoline-copper, a novel chelate fungicide against Fusarium graminearum
}

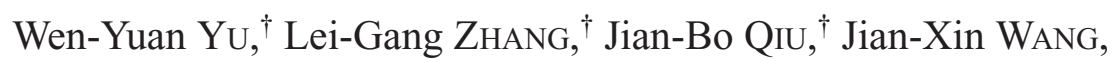 \\ Chang-Jun CHEN and Ming-guo ZHOU* \\ Department of Pesticide Science, College of Plant Protection, Nanjing Agricultural University, Jiangsu Key Laboratorys of \\ Pesticide Science, and Integrated Management of Crop Diseases and Pests (Ministry of Education), \\ Nanjing 210095, Jiangsu Province, China
}

(Received February 28, 2011; Accepted April 29, 2011)

\begin{abstract}
The efficacy of carbendazim-8-oxyquinoline-copper (BCOC), which is a chelate of carbendazim (MBC) and oxine-copper (BHC), was compared with that of $\mathrm{MBC}$ and $\mathrm{BHC}$ for control of Fusarium graminearum. In vitro inhibition of MBC-resistant $\left(\mathrm{MBC}^{\mathrm{R}}\right)$ strains was greater with $\mathrm{BCOC}$ than with $\mathrm{MBC}$ or $\mathrm{BHC}$, or the mixture of $\mathrm{MBC}$ and $\mathrm{BHC}$; the minimum inhibitory concentration (MIC) of MBC-high-resistant strains for BCOC was 10 times lower than the MIC for MBC. Appearance of germ tubes of $F$ graminearum was similar after treating with $\mathrm{BCOC}$ or $\mathrm{MBC}$. The $\mathrm{EC}_{50}$ of BCOC was $1.29 \pm 0.61 \mu \mathrm{g} / \mathrm{mL}$ against $124 \mathrm{~F}$. graminearum field strains collected in 2010 and $3.23 \pm 0.41 \mu \mathrm{g} / \mathrm{mL}$ against 127 F. graminearum $\mathrm{MBC}^{\mathrm{R}}$ field strains collected between 2000 and 2010. BCOC provided best protective and curative control of Fusarium head blight on wheat artificially inoculated with both $\mathrm{MBC}^{\mathrm{S}}$ (MBC sensitive) and $\mathrm{MBC}^{\mathrm{R}}$ strains in the field. To explain the high efficacy of BCOC, we hypothesize that the 8-oxyquinoline-copper in BCOC changes the molecule's structure and thereby increases the interaction between the carbendazim radical in BCOC and the $\beta_{2}$-tubulin protein in F. graminearum. BCOC has substantial potential for the synthesis of new fungicides for disease control and resistance management. (C) Pesticide Science Society of Japan
\end{abstract}

Keywords: carbendazim-8-oxyquinoline-copper, carbendazim, oxine-copper, Fusarium graminearum, resistant, susceptibility.

\section{Introduction}

Fusarium head blight (FHB) results in the contamination of wheat and other cereal crops with mycotoxins such as deoxynivalenol (DON), nivalenol (NIV), T-2 toxin, zearalenone (ZEA), and their derivatives; these mycotoxins threaten food safety and are a global concern. ${ }^{1,2)}$ In China, where FHB is mainly caused by Fusarium graminearum, control of FHB for over 30 years has largely depended on the application of carbendazim (methyl benzimidazole-2-yl carbamate or MBC, Fig. 1a). ${ }^{3,4)}$ The continued use of MBC, however, is threatened by the development of MBC resistance in $F$ graminearum populations. ${ }^{5,6)}$ Previous studies demonstrated that the resist-

\footnotetext{
* To whom correspondence should be addressed. E-mail:mgzhou@njau.edu.cn

$\dagger$ These authors contributed equally to this work. Published online July 17, 2011

(C) Pesticide Science Society of Japan
}

ance was based on site-directed mutations in the $\beta_{2}$-tubulin gene. ${ }^{7)}$ Alternatives to $\mathrm{MBC}$ with novel modes of action are therefore needed to control FHB.

One alternative to $\mathrm{MBC}$ is carbendazim-8-oxyquinolinecopper (benzimidazole-2-carbamate-8-oxyquinoline-copper or BCOC, Fig. 1c), which is a chelate of MBC and oxine-copper (bis-(8-hydroxyquinolinato)-copper II or BHC, Fig. 1b). $\mathrm{BHC}$ is the most active of the metal oxinates and has been used as an agricultural fungicide for many years. ${ }^{8-10)} \mathrm{BHC}$ is

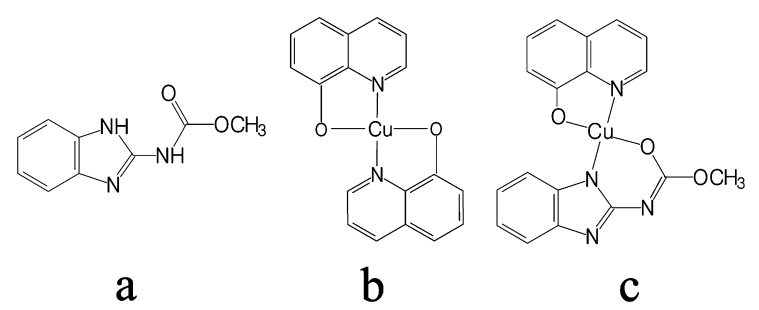

Fig. 1. Chemical structures of (a) MBC, (b) BHC, and (c) BCOC. 
more effective, more durable (i.e., less likely to select for resistance), and less toxic to nontarget organisms than many other copper compounds but has been used infrequently. ${ }^{11)}$

The objectives of this research were to: (1) compare the in vitro sensitivity of $F$. graminearum to $\mathrm{BCOC}, \mathrm{BHC}$, and $\mathrm{MBC}$; (2) compare the efficacy of BCOC, BHC, and MBC for control of FHB in the field, and (3) investigate the fungicidal mechanism of BCOC.

\section{Materials and Methods}

\section{Fungicides and media}

BCOC as a nonformulated compound (98.0\% pure) and as a $50.0 \%$ wettable powder (WP) was provided by Shanghai Bright Green Chemical Industry Co. Ltd., China. MBC as an active compound (98.0\%) and as a 50.0\% WP was provided by Shenyang Chemical Industry Academy, China. BHC as an active compound $(99.0 \%)$ and as a $33.5 \%$ suspension concentrate (SC) was provided by Zhejiang Haizheng Chemical Industry Co. Ltd., China.

For in vitro experiments, nonformulated $\mathrm{BCOC}$ and $\mathrm{MBC}$ were dissolved in $0.1 \mathrm{M} \mathrm{HCl}$ whereas nonformulated $\mathrm{BHC}$ was passed through a 600-mesh sieve (pore diameter $23 \mu \mathrm{m}$ ) and then suspended in a mixture of methanol and deionized water $(1: 1, \mathrm{v}: \mathrm{v})$; the BHC suspension was shaken vigorously before use. All stock solutions were prepared at $10,000 \mu \mathrm{g} / \mathrm{mL}$ and stored at $4{ }^{\circ} \mathrm{C}$ in the dark to preserve fungicidal activity. For testing in vitro inhibition of mycelial growth and conidium germination, the fungicides were serially diluted in sterile potato dextrose agar (PDA) at about $50^{\circ} \mathrm{C}$, which was made from $200 \mathrm{~g}$ potato extract, $15 \mathrm{~g}$ agar, and $20 \mathrm{~g}$ dextrose per liter of $\mathrm{H}_{2} \mathrm{O}$. ${ }^{4,7)}$

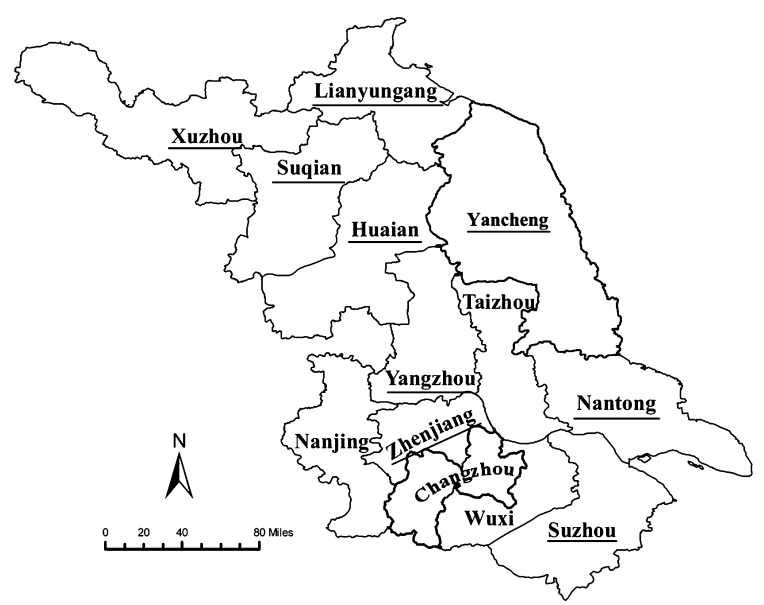

Fig. 2. Map of Jiangsu Province of P. R. China. Areas where F. graminearum was collected in May 2010 are underlined.

\section{Origin of $\mathrm{F}$. graminearum isolates}

Of the $251 \mathrm{~F}$. graminearum isolates used for determination of baseline sensitivitiy to BCOC (see section 2.4), 124 were randomly selected from 895 isolates collected from commercial wheat fields in Jiangsu Province, China in May 2010. These wheat fields were located at least $10 \mathrm{~km}$ from each other and in areas where BCOC had never been used (Fig. 2). Singlemacroconidia isolates of $F$. graminearum were obtained using standard procedures as described by Chen et al. ${ }^{12)}$ The numbers of isolates obtained from each city of Jiangsu Province were: Zhenjiang (5), Suzhou (23), Nantong (17), Suqian (12), Huaian (25), Yangzhou (11), Yancheng (21), Lianyungang (6), Xuzhou (4). The other 127 isolates were collected from

Table 1. Effect of $\mathrm{MBC}, \mathrm{BCOC}$, and $\mathrm{BHC}$ (as indicated by $\mathrm{EC}_{50}$ and $\mathrm{MIC}$ values) on the in vitro mycelial growth of $F$. graminearum strains that differed in MBC susceptibility

\begin{tabular}{|c|c|c|c|c|c|c|c|}
\hline \multirow{2}{*}{ Strain } & \multirow{2}{*}{$\begin{array}{l}\text { Mutation site and } \\
\left.\text { phenotype to } \mathrm{MBC}^{a}\right)\end{array}$} & \multicolumn{2}{|c|}{$\mathrm{MBC}$} & \multicolumn{2}{|c|}{$\mathrm{BCOC}$} & \multicolumn{2}{|c|}{$\mathrm{BHC}$} \\
\hline & & $\mathrm{EC}_{50}$ & $\mathrm{MIC}^{b)}$ & $\mathrm{EC}_{50}$ & MIC & $\mathrm{EC}_{50}$ & MIC \\
\hline JT04 & 198, HR & $5.6 \mathrm{bc}^{\mathrm{c}}$ & $>200$ & $3.8 \mathrm{a}$ & 20 & $14.9 \mathrm{bc}$ & $>200$ \\
\hline ZF43-17 & 198, IHR & $1.3 \mathrm{~cd}$ & 200 & $2.4 \mathrm{ab}$ & 20 & $13.9 \mathrm{bc}$ & $>200$ \\
\hline NT-7 & $200, \mathrm{MR}$ & $7.2 \mathrm{~b}$ & 50 & $2.2 \mathrm{ab}$ & 20 & $17.2 \mathrm{bc}$ & $>200$ \\
\hline $\mathrm{T} 1$ & $200, \mathrm{MR}$ & $7.3 \mathrm{~b}$ & 50 & $2.3 \mathrm{ab}$ & 20 & $11.3 \mathrm{c}$ & 200 \\
\hline R9 & $167, \mathrm{MR}$ & $6.6 \mathrm{~b}$ & 70 & $2.3 \mathrm{ab}$ & 20 & $9.6 \mathrm{c}$ & $>200$ \\
\hline ZF52 & $167, \mathrm{MR}$ & $9.5 \mathrm{~b}$ & 50 & $2.4 \mathrm{ab}$ & 10 & $14.3 \mathrm{bc}$ & $>200$ \\
\hline ZF52-7 & $167+17, \mathrm{IHR}$ & $43.4 \mathrm{a}$ & $>200$ & $2.9 \mathrm{ab}$ & 25 & $24.3 \mathrm{~b}$ & $>200$ \\
\hline 2021 & wild-type, $S$ & $0.6 \mathrm{~d}$ & 1.4 & $1.1 \mathrm{~b}$ & 2.5 & $20.0 \mathrm{bc}$ & $>200$ \\
\hline DB6 & $\beta_{1}$-tubulin knockout, $\mathrm{S}$ & $0.8 \mathrm{~d}$ & 1.4 & $1.3 \mathrm{~b}$ & 2.5 & $26.2 \mathrm{~b}$ & $>200$ \\
\hline DN83 & $\beta_{2}$-tubulin knockout, $\mathrm{S}$ & $0.1 \mathrm{~d}$ & 0.4 & $0.2 \mathrm{~b}$ & 0.6 & $41.0 \mathrm{a}$ & $>200$ \\
\hline
\end{tabular}

${ }^{a)}$ HR: highly resistant; IHR: induced highly resistant; MR: moderately resistant; S: sensitive; JT04, NT-7, T1, R9, ZF52, and 2021 were wild-type strains; ZF43-17, ZF52-7, DB6, and DN83 were artificially modified strains. ${ }^{b)}$ Units for $\mathrm{EC}_{50}$ and MIC are $\mu \mathrm{g} / \mathrm{mL} .{ }^{c)}$ Values in a column followed by the same letter are not significantly different according to Fisher's LSD test $(p=0.05)$. 
various provinces in China from 2001 to 2010 and were determined to be MBC resistant (data not shown).

In addition to the 251 strains referred to in the previous paragraph, 10 other strains of $F$. graminearum were collected from different provinces of China from 2000 to 2010 and have been maintained in our laboratory. Seven were MBC-resistant $\left(\mathrm{MBC}^{\mathrm{R}}\right)^{3,7)}$ and three were sensitive $\left(\mathrm{MBC}^{\mathrm{S}}\right)^{3,7,13)}$ (Table 1). Some of these strains were artificially modified by induction (data not shown).

3. Mycelial growth of $\mathrm{F}$. graminearum in vitro as affected by $B C O C, M B C$, and $B H C$

The 10 strains listed in Table 1 were used for this experiment. A 5-mm diameter mycelial disk cut from the edge of an actively growing culture ( 3 days old) of each strain was placed in the center of a 9-cm-diameter Petri dish containing PDA plus fungicide. The concentrations of MBC were $0.1,0.2,0.4$, $0.6,0.8,1.0,1.2,1.3$ and $1.4 \mu \mathrm{g} / \mathrm{mL}$ for the $\mathrm{MBC}^{\mathrm{S}}$ strains 2021 and DB6; 0.01, 0.02, 0.04, 0.08, 0.12, 0.16, 0.2, 0.3 and $0.4 \mu \mathrm{g} / \mathrm{mL}$ for the $\mathrm{MBC}^{\mathrm{S}}$ strain $\mathrm{DN} 83$; and $1.56,3.13,6.25$, $12.5,25,50,60,70,80,90,100,150$ and $200 \mu \mathrm{g} / \mathrm{mL}$ for the $\mathrm{MBC}^{\mathrm{R}}$ strains. The concentrations of $\mathrm{BCOC}$ were $0.6,0.8$, $1.0,1.2,1.4,1.6,1.8,2.0,2.1,2.2,2.3,2.4$, and $2.5 \mu \mathrm{g} / \mathrm{mL}$ for strains 2021 and DB6; 0.01, 0.05, 0.1, 0.15, 0.2, 0.25, 0.3, $0.4,0.5$, and $0.6 \mu \mathrm{g} / \mathrm{mL}$ for strain DN83; and $1,2,3,4,5,6$, $7,8,9,10,15,20$ and $25 \mu \mathrm{g} / \mathrm{mL}$ for the $\mathrm{MBC}^{\mathrm{R}}$ strains. The concentrations of BHC were 2.5, 5, 10, 20, 30, 40, 50, 100, and $200 \mu \mathrm{g} / \mathrm{mL}$ for all $10 F$ graminearum strains. Control treatments contained PDA without fungicide and the experiment was performed twice with three replicates. After 3 days at $25^{\circ} \mathrm{C}$, colony diameter of each strain was measured with the original mycelial disk diameter $(5 \mathrm{~mm})$ subtracted from this measurement. Percentage inhibition was calculated as $(1-a / b) \times 100$, where $a$ is the colony diameter in Petri dishes with fungicide and $b$ is the mean colony diameter in Petri dishes without fungicide. The median effective concentration $\left(\mathrm{EC}_{50}\right)$ values was calculated, and the minimum inhibitory concentration (MIC), i.e., the minimum concentration that completely inhibited mycelial growth, was determined as the concentration at which no mycelial growth was observed. ${ }^{3,7)}$

A mixture of $\mathrm{MBC}$ and $\mathrm{BHC}$ (referred to as $\mathrm{M} \& \mathrm{~B}$ ) was also used in this experiment. The molecular ratio of MBC to $\mathrm{BHC}$ was $2: 1$, which is the same ratio of quinoline to carbendazim in BCOC. M\&B was tested at 10 and $50 \mu \mathrm{g} / \mathrm{mL}$. The effect of M\&B against the seven $\mathrm{MBC}^{\mathrm{R}}$ strains listed in Table 1 (with three replicate plates per treatment) was compared with that of $\mathrm{BCOC}$ at the same concentrations.

4. Germination of F. graminearum in vitro as affected by $B C O C, M B C$, and $B H C$

Strain 2021 (sensitive to MBC, MBC, Table 1) and JT04 (highly resistant to $\mathrm{MBC}, \mathrm{MBC}^{\mathrm{HR}}$, Table 1) were grown in 150 -mL flasks containing 3\% mung bean filtrate (filtrate of 30 $\mathrm{g}$ mung bean in $1 \mathrm{~L}_{2} \mathrm{O}$ ). The flasks with medium, which were inoculated with 10 mycelial disks, were shaken at 170 rpm at $25^{\circ} \mathrm{C}$ and with a 12 -hr photoperiod. After 5 days, conidia were collected and rinsed, and their concentration was adjusted to $1 \times 10^{5} \mathrm{CFU} / \mathrm{ml}$ with sterile water. A $20-\mu \mathrm{L}$ volume of the conidial suspension was spread on a $20 \times 20 \mathrm{~mm}$ coverglass, which was placed on cellophane on the surface of PDA plates with or without (control) fungicide; before placement on the cellophane, the coverslips were inverted so that the side with conidia was in contact with the cellophane. For determination of inhibitory effects, the concentration of BCOC and BHC in the agar was 1.5 and $5 \mu \mathrm{g} / \mathrm{mL}$, respectively. For determination of completely inhibitive effects, the concentrations of BCOC and BHC in the agar were 5 and $10 \mu \mathrm{g} / \mathrm{mL}$, respectively. Because a high concentration of $\mathrm{MBC}$ caused no inhibition of conidium germination of JT04, MBC was only used at $100 \mu \mathrm{g} / \mathrm{mL}$, whereas the concentration for determination of the inhibitory and completely inhibitive effects was 1.0 and 5 $\mu \mathrm{g} / \mathrm{mL}$ for strain 2021 respectively. There were three replicate coverslips for each treatment. After the coverslips with conidia had been on the agar for $8 \mathrm{hr}$ at $25^{\circ} \mathrm{C}$ and without illumination, the conidia and germlings were photographed at $10 \times 40$ magnification with an OLYMPUS IX71 microscope equipped with an OLYMPUS DP72 lens. Image-Por Express version 6.0.0.319 (Media Cybernetics Inc.) was used for acquisition of photomicrographs at $4140 \times 3096$ pixels.

\section{Baseline $E C_{50}$ values of $B C O C$ against $\mathrm{F}$. gramin- earum}

Baseline $\mathrm{EC}_{50}$ values (i.e., $\mathrm{EC}_{50}$ values for $F$. graminearum populations that had never been exposed to BCOC) were determined for the 124 isolates of $F$. graminearum isolates collected from Jiangsu Province in May 2010, as described by Wang et al. ${ }^{14)} \mathrm{EC}_{50}$ values were determined by measuring mycelial growth in agar containing $\mathrm{BCOC}$ at $0,0.1,0.2,0.4$, $0.8,1.6,3.2$, and $6.4 \mu \mathrm{g} / \mathrm{mL}$, as described in section 2.3 .

Baseline $\mathrm{EC}_{50}$ values of $\mathrm{BCOC}$ were also determined for the other $127 \mathrm{~F}$. graminearum isolates that were collected from different provinces of China between 2000 and 2010 and that had been determined to be resistant to $\mathrm{MBC}$ (MIC $>2$ $\mu \mathrm{g} / \mathrm{mL}$, unpublished data). BCOC concentrations of these resistant isolates were $0,1,2,3,4,5,6$, and $7 \mu \mathrm{g} / \mathrm{mL}$.

\section{Efficacy of $B C O C$ in vivo}

F. graminearum strains $2021\left(\mathrm{MBC}^{\mathrm{S}}\right)$ and $\mathrm{JT} 04\left(\mathrm{MBC}^{\mathrm{HR}}\right)$ and F. graminearum-susceptible wheat cultivar Yangmai 158 were used to compare the efficacy of BCOC (50\% WP), MBC (50\% WP), and BHC (33.5\% SC) against FHB in vivo. The experiment was conducted at a field site $(7.9 \times 4.4 \mathrm{~m})$ planted with wheat at the Pailou Experimental Centre of Nanjing Agricultural University. The wheat was planted on 30 October 2009 in small circular plots $(0.2 \mathrm{~m}$ in diameter) with 10 plants per plot, and plots at $0.5 \mathrm{~m}$ intervals. A randomized complete block design was used. There were seven fungicide treatments: two rates ( 400 and $800 \mu \mathrm{g} / \mathrm{mL}$ ) of each of the three 
fungicides and a water control. Application was processed the day before and after artificial inoculation with each of the two strains, respectively. Overall, there were 28 treatments (7 combinations of fungicide and rate + water control $\times 2$ application times $\times 2$ strains of the fungus), and each treatment was represented by three replicate plots, giving 84 plots. On day 1 (28 April 2010), the plants in three replicate plots (42 of the 84) were sprayed with $50 \mathrm{ml}$ fungicide or water; the wheat was flowering at this time. When the fungicide was applied, a plastic board was used to prevent the fungicide from contacting plants in adjacent plots, and all 10 plants in each plot were completely sprayed. On day 2 , one mid-level spikelet on each plant in all 84 plots was injected with $10 \mu \mathrm{L}$ conidial suspension $\left(1 \times 10^{5} \mathrm{CFU} / \mathrm{mL}\right)$ of either strain 2021 or strain JT04. On day 3 , plants that had not been sprayed on day 1 (plants in the remaining 42 plots) were sprayed with the same fungicides or with water. Fungicide application on day 1 (1 day before inoculation) was used to measure protective control while application on day 3 ( 1 day after inoculation) was used to measure curative control. The conditions in the field were suitable for FHB development $\left(25-30^{\circ} \mathrm{C}\right.$ and $\left.85 \% \mathrm{RH}\right)$, and no natural FHB developed in this field. FHB severity was rated 20 days after inoculation using the following scale: 0 , no visible symptoms; 1, 1-3\%; 2, 4-10\%; 3, 11-25\%; 4, 26-50\%; 5, $51-75 \% ; 6,>75 \%$ of the spikelets showed FHB symptoms. ${ }^{15)}$ The disease index $=[n(1)+n(2)+n(3)+n(4)+n(5)+n(6)] /$ number of spikelets infected $\times 100$, where $\mathrm{n}$ indicates the number of infected plants rated as $1,2,3,4,5$, or 6 . Percentage disease control was calculated with the following formula: Percentage disease control $=[1-($ disease index of the treatment $) /($ disease index of water-treated control) $] \times 100$.

\section{Statistical analysis}

All data were subjected to analysis of variance (ANOVA). $\mathrm{EC}_{50}$ values were estimated after log-logit transformation of dose-response data. Means were separated with Fisher's least significant difference (LSD) at $p=0.05$. The software used was SAS GLM (SAS Institute Inc., Cary, NC).

\section{Results}

1. In vitro sensitivity of $\mathrm{F}$. graminearum mycelial growth to $B C O C, B H C$, and $M B C$

There was no evident regularity of $\mathrm{MBC}^{\mathrm{R}}$ strains for $\mathrm{MBC}$ and $\mathrm{BCOC}$ based on $\mathrm{EC}_{50}$ values, but the MIC values of $\mathrm{MBC}^{\mathrm{MR}}$ and $\mathrm{MBC}^{\mathrm{HR}}$ strains were obviously classified for $\mathrm{MBC}$ (Table 1); however, $\mathrm{EC}_{50}$ and $\mathrm{MIC}$ values of $\mathrm{MBC}^{\mathrm{MR}}$ and $\mathrm{MBC}^{\mathrm{HR}}$ strains were not significantly different for $\mathrm{BCOC}$. $\mathrm{BCOC}$ was more inhibitive than $\mathrm{MBC}$ or $\mathrm{BHC}$ based on $\mathrm{EC}_{50}$ and MIC values except ZF43-17, the $\mathrm{EC}_{50}$ of which was slightly lower for MBC than for BCOC (Table 1), whereas the $\mathrm{EC}_{50}$ and $\mathrm{MIC}$ values of $\mathrm{MBC}^{\mathrm{S}}$ strains were slightly higher for BCOC than for MBC. BHC was much less inhibitory than BCOC or MBC (Table 1).

Mycelial growth of all $7 \mathrm{MBC}^{\mathrm{R}}$ strains was strongly inhibited by $10 \mu \mathrm{g} / \mathrm{mL}$ BCOC and completely inhibited by 50 $\mu \mathrm{g} / \mathrm{mL} \mathrm{BCOC}$, whereas $50 \mu \mathrm{g} / \mathrm{mL} \mathrm{M} \& \mathrm{~B}$ could hardly provide greater inhibition than $10 \mu \mathrm{g} / \mathrm{mL}$ BCOC. There was no significant difference in inhibition against strains treated with BCOC (Table 2).

2. Germination of $\mathrm{F}$. graminearum in vitro as affected by $B C O C, M B C$, and $B H C$

Inhibition of conidium germination and germling growth of $\mathrm{MBC}^{\mathrm{R}}$ strain JT04 was much greater with BCOC than with MBC (Fig. 3a-d), whereas inhibition of $\mathrm{MBC}^{\mathrm{S}}$ strain 2021 was similar for the two fungicides (Fig. $3 \mathrm{~g}-\mathrm{k}$ ). BCOC-treated and $\mathrm{MBC}$-treated conidia that germinated produced multiple, distorted germ tubes and tended to germinate from the middle of the conidia (Fig. 3b, c, h, j). Although $10 \mu \mathrm{g} / \mathrm{mL} \mathrm{BHC}$ could inhibit the germination of the two strains completely, it caused no change to the appearance of germ tubes (Fig. 3e, f, $1, \mathrm{~m})$. None of the three fungicides induced deformity of the

Table 2. Inhibition of mycelial growth of MBC-resistant F. graminearum strains by BCOC and M\&B (MBC $+\mathrm{BHC})$

\begin{tabular}{llllll}
\hline \multirow{2}{*}{ Strain } & Mutation site and & & \multicolumn{3}{c}{ Percentage inhibition (means \pm SD) } \\
\cline { 3 - 6 } & MBC phenotype $^{a)}$ & BCOC at $10 \mu \mathrm{g} / \mathrm{mL}$ & M\&B $^{b)}$ at $10 \mu \mathrm{g} / \mathrm{mL}$ & BCOC at $50 \mu \mathrm{g} / \mathrm{mL}$ & $\mathrm{M} \& \mathrm{~B}$ at $50 \mu \mathrm{g} / \mathrm{mL}$ \\
\hline JT04 & $198, \mathrm{HR}$ & $90.6 \pm 0.05 \mathrm{~b}^{c)}$ & $69.8 \pm 0.07 \mathrm{~b}$ & $100 \pm 0.0 \mathrm{a}$ & $81.7 \pm 0.10 \mathrm{c}$ \\
ZF43-17 & 198, IHR & $90.3 \pm 0.07 \mathrm{~b}$ & $82.1 \pm 0.10 \mathrm{a}$ & $100 \pm 0.0 \mathrm{a}$ & $94.7 \pm 0.02 \mathrm{a}$ \\
ZF52-7 & $167+17$, IHR & $91.0 \pm 0.05 \mathrm{~b}$ & $27.0 \pm 0.14 \mathrm{e}$ & $100 \pm 0.0 \mathrm{a}$ & $51.0 \pm 0.12 \mathrm{~d}$ \\
ZF52 & 167, MR & $100 \pm 0.0 \mathrm{a}$ & $40.6 \pm 0.05 \mathrm{~d}$ & $100 \pm 0.0 \mathrm{a}$ & $88.5 \pm 0.03 \mathrm{~b}$ \\
R9 & 167, MR & $91.2 \pm 0.07 \mathrm{~b}$ & $68.0 \pm 0.25 \mathrm{~b}$ & $100 \pm 0.0 \mathrm{a}$ & $90.3 \pm 0.03 \mathrm{~b}$ \\
NT-7 & 200, MR & $90.4 \pm 0.10 \mathrm{~b}$ & $69.9 \pm 0.30 \mathrm{~b}$ & $100 \pm 0.0 \mathrm{a}$ & $90.2 \pm 0.04 \mathrm{~b}$ \\
T1 & 200, MR & $89.6 \pm 0.38 \mathrm{~b}$ & $49.9 \pm 0.06 \mathrm{c}$ & $100 \pm 0.0 \mathrm{a}$ & $90.4 \pm 0.02 \mathrm{~b}$ \\
\hline
\end{tabular}

a) HR: highly resistant; IHR: induced highly resistant; MR: moderately resistant; JT04, ZF52, R9, NT-7 and T1 were wild-type strains; ZF43-17 and ZF52-7 were artificially modified strains. ${ }^{b)}$ Molecular ratio of MBC to BHC $=2: 1{ }^{c}{ }^{c}$ Values in a column followed by the same letter are not significantly different according to Fisher's LSD test $(p=0.05)$. 


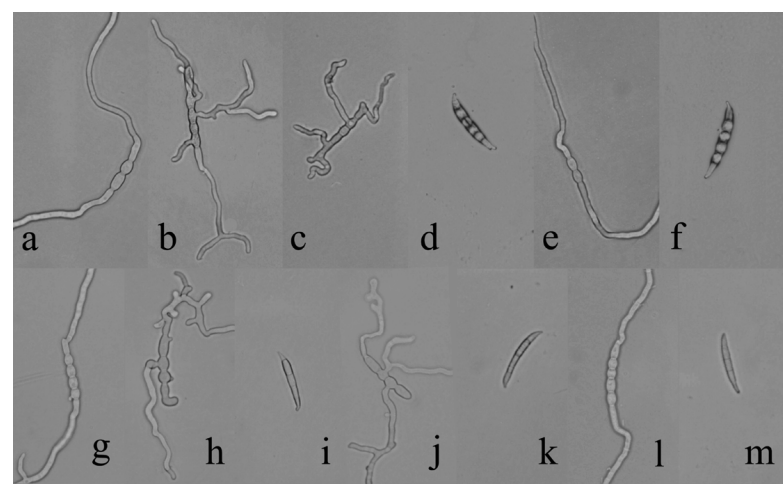

Fig. 3. Photomicrographs of conidia and germlings of $F$. graminearum exposured to $\mathrm{MBC}, \mathrm{BCOC}$, and $\mathrm{BHC}$ on agar for $8 \mathrm{hr}$ at $25^{\circ} \mathrm{C}$. Photographs marked with a-f refer to strain JT04 $\left(\mathrm{MBC}^{\mathrm{HR}}\right)$ whereas g-m refer to strain $2021\left(\mathrm{MBC}^{\mathrm{S}}\right)$. (a) Control of JT04, without fungicides; (b) JT04 and (treated with) $100 \mu \mathrm{g} / \mathrm{mL} \mathrm{MBC;} \mathrm{(c)} \mathrm{JT04} \mathrm{and} 1.5$ $\mu \mathrm{g} / \mathrm{mL} \mathrm{BCOC}$; (d) JT04 and $5 \mu \mathrm{g} / \mathrm{mL} \mathrm{BCOC;} \mathrm{(e)} \mathrm{JT04} \mathrm{and} 5 \mu \mathrm{g} / \mathrm{mL}$ $\mathrm{BHC}$; (f) JT04 and $10 \mu \mathrm{g} / \mathrm{mL} \mathrm{BHC;} \mathrm{(g)} \mathrm{control} \mathrm{of} \mathrm{2021,} \mathrm{without}$ fungicides; (h) 2021 and $1.0 \mu \mathrm{g} / \mathrm{mL} \mathrm{MBC;} \mathrm{(i)} 2021$ and $5 \mu \mathrm{g} / \mathrm{mL}$ MBC; (j) 2021 and $1.5 \mu \mathrm{g} / \mathrm{mL} \mathrm{BCOC;} \mathrm{(k)} 2021$ and $5 \mu \mathrm{g} / \mathrm{mL} \mathrm{BCOC;}$ (1) 2021 and $5 \mu \mathrm{g} / \mathrm{mL}$ BHC; (m) 2021 and $10 \mu \mathrm{g} / \mathrm{mL}$ BHC.
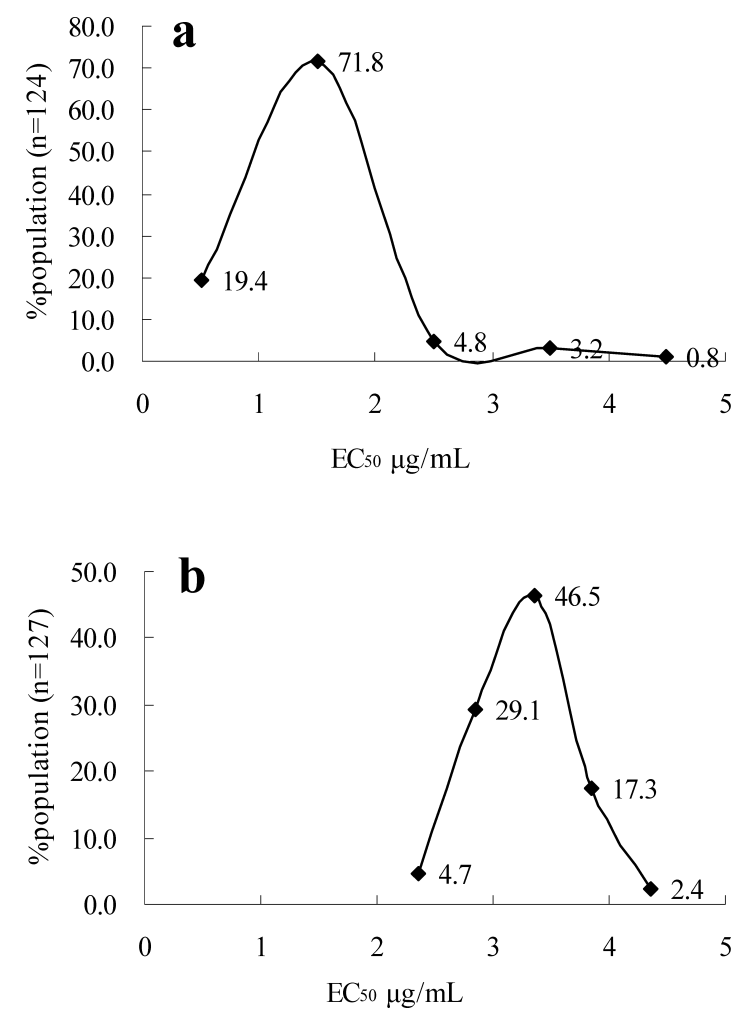

Fig. 4. Frequency distribution of sensitivity of $251 \mathrm{~F}$. graminearum isolates to BCOC on PDA. (a) Field strains (124) with unknown sensitivity to MBC collected from Jiangsu Province, China in May 2010; (b) Field strains (127) collected from different provinces of China between 2000 and 2010 and determined to be resistant to MBC (MIC> $2 \mu \mathrm{g} / \mathrm{mL})$. conidia at their lethal concentrations (Fig. 3d, f, i, k, m).

\section{Baseline sensitivity to $B C O C$}

The $\mathrm{EC}_{50}$ values of strains with unknown sensitivity to $\mathrm{MBC}$ and collected from Jiangsu Province in May 2010 ranged from 0.92 to $4.26 \mu \mathrm{g} / \mathrm{mL}$ and averaged $1.29 \pm 0.61 \mu \mathrm{g} / \mathrm{mL}$, representing a sensitivity range of 4.63 times, and were divided into 5 groups with the same range: $0-1,1-2,2-3,3-4$, $4-5 \mu \mathrm{g} / \mathrm{mL}$ (Fig. 4a). The $\mathrm{EC}_{50}$ values of $\mathrm{MBC}^{\mathrm{R}}$ strains collected from different provinces in China between 2000 and 2010 ranged from 2.21 to $4.50 \mu \mathrm{g} / \mathrm{mL}$ and averaged $3.23 \pm 0.41$ $\mu \mathrm{g} / \mathrm{mL}$, representing a sensitivity range of 2.04 times, and were also divided into 5 groups with the same range: 2.1-2.6, $2.6-3.1,3.1-3.6,3.6-4.1,4.1-4.6 \mu \mathrm{g} / \mathrm{mL}$ (Fig. 4b). The frequency distribution of $\mathrm{BCOC} \mathrm{EC}_{50}$ values was unimodal for both sets of $F$. graminearum populations, indicating that the data in Fig. 4a could be used as a baseline for monitoring the shift of sensitivity in F. graminearum populations to BCOC (Fig. 4).

\section{Efficacy of $B C O C$ in vivo}

All of the inoculated plants in control plots were infected with disease intensity of $58.0 \%$. Overall, control of FHB in vivo was better with BCOC than with MBC or BHC (Table 3). Although protective control of the susceptible strain was a little higher with $\mathrm{BCOC}$ than with $\mathrm{MBC}$, there was no significant difference between them as expected. Protective control of the

Table 3. Control of FHB by BCOC ( $50 \% \mathrm{WP})$, MBC ( $50 \%$ $\mathrm{WP})$, and $\mathrm{BHC}(33.5 \% \mathrm{SC})$ in vivo ${ }^{a)}$

\begin{tabular}{|c|c|c|c|c|c|}
\hline \multirow{2}{*}{ Fungicide } & \multirow{2}{*}{$\begin{array}{l}\text { Dosage } \\
(\mu \mathrm{g} / \mathrm{mL})\end{array}$} & \multicolumn{2}{|c|}{$\begin{array}{l}\text { Protective disease } \\
\text { control }(\%)^{b)}\end{array}$} & \multicolumn{2}{|c|}{$\begin{array}{c}\text { Curative disease } \\
\text { control (\%) }\end{array}$} \\
\hline & & $2021^{c)}$ & JT04 & 2021 & JT04 \\
\hline $\mathrm{BCOC}$ & 800 & $87.5 \mathrm{a}$ & $72.4 \mathrm{a}$ & $73.5 \mathrm{a}$ & $71.8 \mathrm{a}$ \\
\hline $\mathrm{BCOC}$ & 400 & $82.8 \mathrm{a}$ & $71.8 \mathrm{a}$ & $72.4 \mathrm{a}$ & $65.5 \mathrm{~b}$ \\
\hline $\mathrm{MBC}$ & 800 & $84.3 \mathrm{a}$ & $51.7 \mathrm{~cd}$ & $62.1 \mathrm{~b}$ & $49.8 \mathrm{~d}$ \\
\hline $\mathrm{MBC}$ & 400 & $81.4 \mathrm{a}$ & $48.3 \mathrm{~d}$ & $58.6 \mathrm{~b}$ & $46.7 \mathrm{~d}$ \\
\hline $\mathrm{BHC}$ & 800 & $55.2 \mathrm{~b}$ & $58.6 \mathrm{~b}$ & $48.3 \mathrm{c}$ & $58.6 \mathrm{c}$ \\
\hline $\mathrm{BHC}$ & 400 & $46.7 \mathrm{~b}$ & $55.7 \mathrm{bc}$ & $44.8 \mathrm{c}$ & $55.2 \mathrm{c}$ \\
\hline
\end{tabular}

a) On day 1, individual wheat plants were treated with fungicides or water to measure the protective control. Half of the plants were artificially inoculated on day 2 with a conidial suspension of either an $\mathrm{MBC}^{\mathrm{S}}$ wild-type strain (2021) or an $\mathrm{MBC}^{\mathrm{R}}$ wild-type strain (JT04) of F. graminearum. On day 3, the other half of the plants were treated with the same fungicides or water to measure curative control. ${ }^{b)}$ Percentage disease control is relative to inoculated plants that were treated with water rather than with fungicide. ${ }^{c}$ Within a column, means followed by the same letter are not significantly different according to Fisher's LSD test $(p=0.05)$. 
resistant strain was significantly greater with $\mathrm{BCOC}$ than with $\mathrm{MBC}$ and curative control was always greater with $\mathrm{BCOC}$ than with the other two fungicides (Table 3 ). In addition, control of the sensitive strain was better than the resistant strain with $\mathrm{BCOC}$ and $\mathrm{MBC}$. Although $\mathrm{BHC}$ is known as a preventive fungicide, it provided some curative activity here. This might mainly because the time between inoculation and treatment was too limited for the strains to infect.

\section{Discussion}

Fungicides with a similar structure tend to develop cross-resistance, as has been documented for the benzimidazole fungicides carbendazim, thiabendazole, and benomyl. ${ }^{16,17)}$ $\mathrm{BCOC}, \mathrm{MBC}$, and $\mathrm{BHC}$ also have structural similarities, and in this research we determined the efficacy of BCOC, MBC, and $\mathrm{BHC}$ against $F$. graminearum in vitro and in the field. Even though BCOC shares structural elements with $\mathrm{MBC}$, inhibition of $\mathrm{MBC}^{\mathrm{R}}$ strains was much greater with $\mathrm{BCOC}$ than with $\mathrm{MBC}$. The efficacy of $\mathrm{BCOC}$ against $\mathrm{MBC}^{\mathrm{S}}$ strains was almost equal to that of $\mathrm{MBC}$ and was much better than that of $\mathrm{BHC}$, which also has some structural similarity to $\mathrm{BCOC}$. However, the inhibition of mycelial growth of $\mathrm{MBC}^{\mathrm{R}}$ strains was coincidentally a little worse than $\mathrm{MBC}^{\mathrm{S}}$ strains for BCOC. These phenomena suggested an extremely low level of cross-resistance, indicating that the benzimidazole-2-carbamate component played a role in BCOC. Furthermore, if 8oxyquinoline-copper was the main component responsible for inhibition by BCOC, inhibition by $\mathrm{BHC}$ should have been greater because $\mathrm{BHC}$ contains one more 8-oxyquinoline component than $\mathrm{BCOC}$. We therefore hypothesize that the component in $\mathrm{BCOC}$ that was mainly responsible for its fungicidal activity was benzimidazole-2-carbamate. This inference was also supported by the appearance of germinated conidia, which was similar after treatment with $\mathrm{BCOC}$ and $\mathrm{MBC}$. In other words, the activity of $\mathrm{BCOC}$ cannot be explained as resulting from the simple combination of $\mathrm{MBC}$ and $\mathrm{BHC}$. Rather, the mechanism of $\mathrm{BCOC}$ seems to be similar to but also distinct from that of $\mathrm{MBC}$.

In another of our studies, the results were similar with Botrytis cinerea and Sclerotinia sclerotiorum in that BCOC showed much better inhibition against $\mathrm{MBC}^{\mathrm{R}}$ strain than $\mathrm{MBC}$, and slightly lower efficacy against $\mathrm{MBC}^{\mathrm{S}}$ strain than MBC; BHC acted less well than BCOC or MBC (unpublished data). Although the data were different, the tendency was the same for each pathogen. These results indicated that BCOC do have a somewhat similar mechanism to $\mathrm{MBC}$ and provided further proof of our hypothesis.

Previous studies demonstrated that mutations at codon 167 or 200 of the $\beta_{2}$-tubulin gene lead to $\mathrm{MBC}^{\mathrm{MR}}$, and a mutation at codon 198 alone or accompanied by a mutation at codon 73 leads to $\mathrm{MBC}^{\mathrm{HR}}$. ${ }^{7,18,19)} \mathrm{We}$ assume that mutations at these codons alter the structure of $\beta_{2}$-tubulin protein and thereby reduce the interaction between the protein and the fungicide molecule. If the functional configuration had been similar for
$\mathrm{MBC}$ and $\mathrm{BCOC}, \mathrm{MBC}^{\mathrm{R}}$ strains should have been significantly resistant to $\mathrm{BCOC}$, which was not the case. It is also possible that although the 8-hydroxyquinilato-copper configuration in $\mathrm{BCOC}$ cannot be the main explanation of the fungicide's activity, it might have synergistically interacted with other aspects of the molecule to increase the molecule's activity; however, this is only a primary inference and needs further verification.

In a previous study, the average $\mathrm{EC}_{50}$ value of $\mathrm{MBC}^{\mathrm{R}} F$. graminearum strains for $\mathrm{MBC}$ was $9.2 \pm 1.9 \mu \mathrm{g} / \mathrm{mL}$. ${ }^{5)}$ That value is substantially higher than the average $\mathrm{EC}_{50}$ value for $\mathrm{MBC}^{\mathrm{R}}$ F. graminearum strains for $\mathrm{BCOC}$ in the current study, which was $3.2 \pm 0.4 \mu \mathrm{g} / \mathrm{mL}$. The average $\mathrm{EC}_{50}$ value of $\mathrm{MBC}^{\mathrm{S}}$ strains for $\mathrm{MBC}$, however, was $0.6 \pm 0.01 \mu \mathrm{g} / \mathrm{mL}$ in the previous study, ${ }^{5}$ ) which was substantially lower than that for $\mathrm{BCOC}$ in the current study. Nevertheless, control of $\mathrm{MBC}^{\mathrm{S}}$ and $\mathrm{MBC}^{\mathrm{R}}$ strains by $\mathrm{BCOC}$ was excellent in vivo. In particular, the curative effect against inoculated FHB was much greater with BCOC than with MBC. A larger scale field experiment will be needed in further research.

Previous studies with BHC demonstrated that its fungicidal activity was not affected by organic materials, metals, chelating molecules, or $\mathrm{pH}$ fluctuation and that long-term exposure to $\mathrm{BHC}$ did not elicit resistance. ${ }^{20)}$ Determing whether BCOC has some of these same desirable characteristics will require additional research. Additional research is also needed to determine whether BCOC is safe for applicators and the environment and whether modification of radicals on its benzene ring will increase its fungicidal efficacy or otherwise alter its activity. The results reported here indicate that BCOC could be valuable for the synthesis of new fungicides for disease control in general and for management of fungicide resistance in particular.

\section{Acknowledgements}

This study was sponsored by the National Natural Science Foundation of China (No. 30971891). The authors are especially grateful to Professor B. Jaffee for technical editing of this manuscript.

\section{References}

1) T. Ban and K. Suenaga: Euphytica 113, 87-99 (2000).

2) X. L. Wang, Y. F. Cui, F. Y. Fan, Y. L. Song, J. P. Ren, Q. L. Meng and W. J. Xu: J. Phytopathol. 158, 576-578 (2010).

3) C. J. Chen, J. X. Wang, Q. Q. Luo, S. K. Yuan and M. G. Zhou: Pest Manag. Sci. 63, 1201-1207 (2007).

4) H. K. Li, Y. M. Diao, J. X. Wang, C. J. Chen, J. P. Ni and M. G. Zhou: Crop Prot. 27, 90-95 (2008).

5) M. G. Zhou and J. X. Wang: Acta Phytopathol. Sin. 31, 365-370 (2001).

6) Y. J. Zhang, J. J. Yu, Y. N. Zhang, X. Zhang, C. J. Chen, J. X. Wang, D. W. Hollomom, P. S. Fan and M. G. Zhou: Mol. PlantMicrobe Interact. 22, 1143-1150 (2009).

7) C. J. Chen, J. J. Yu, C. W. Bi, Y. N. Zhang, J. Q. Xu, J. X. Wang and M. G. Zhou: Phytopathoogy 99, 1403-1411 (2009).

8) N. Lisker: Crop Prot. 9, 439-445 (1990). 
9) N. Lisker and A. Meiri: Crop Prot. 11, 155-159 (1992).

10) C. Revellin, P. Leterme and G. Catroux: Biol. Fertil. Soils 16, 211-214 (1993).

11) G. Nicoletti, E. Domalewska and R. Borland: Mycol. Res. 103, 1073-1084 (1999).

12) Y. Chen, H. K. Li, C. J. Chen and M. G. Zhou: Phytoparasitica 36, 326-337 (2008).

13) S. M. Liu, Y. Chen, J. J. Yu, C. J. Chen, J. X. Wang and M. G. Zhou: Pest Manag. Sci. 66, 482-489 (2009).

14) J. X. Wang, H. X. Ma, Y. Chen, X. F. Zhu, W. Y. Yu, Z. H. Tang, C. J. Chen and M. G. Zhou: Crop Prot. 28, 882-886 (2009).

15) L. M. Reid, R. W. Nicol, T. Ouellet, M. Savard, J. D. Miller, J.
C. Young, D. W. Stewart and A. W. Schaafsma: Phytopathology 89, 1028-1037 (1999).

16) W. H. Chung, W. C. Chung, P. F. Ting, C. C. Ru, H. C. Huang and J. W. Huang: J. Phytopathol. 157, 742-747 (2009).

17) P. Leroux, F. Chapeland, D. Desbrosses and M. Gredt: Crop Prot. 18, 687-697 (1999).

18) J. A. Butters and D. W. Hollomon: Pestic. Sci. 55, 501-503 (1999).

19) H. X. Li, Y. J. Lu, J. X. Wang and M. G. Zhou: J. Nanjing Agric. Univ. 25, 41-44 (2002) (in Chinese, with English abstract).

20) G. Nicoletti, E. Domalewska and R. Borland: Mycol. Res. 103, 1085-1097 (1999). 